Intensivmed $2011 \cdot$ 48:290-290

DOI 10.1007/s00390-011-0297-3

(C) Springer-Verlag 2011
A. Gasser · T. Suhai

Springer-Verlag $\mathrm{GmbH}$, Heidelberg

\section{Sehr gute Noten für das neue Konzept der Intensivmedizin und Notfallmedizin}

\section{Ergebnisse der Leserbefragung 2010}

Um künftig noch besser auf Ihre Wünsche eingehen zu können, haben wir Sie in Ausgabe 8/2010 der Intensivmedizin und Notfallmedizin im Rahmen einer Leserbefragung um Ihre Mithilfe gebeten. Ein Jahr nach der Einführung des Leitthemenkonzepts wollten die Herausgeber und die Verlagsredaktion mehr über Ihre Einschätzung der Zeitschrift erfahren.

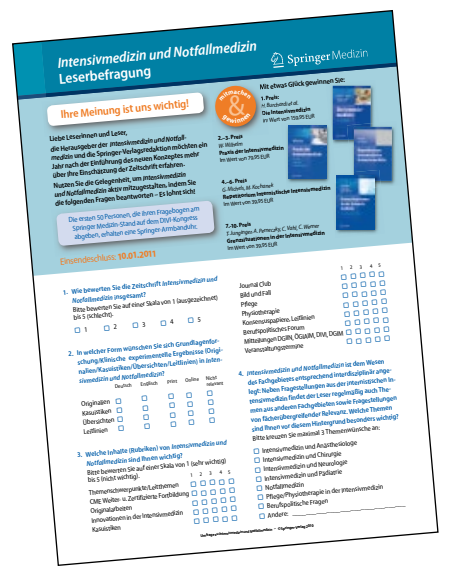

Über 200 Leserinnen und Leser haben sich an der Umfrage beteiligt und wir haben fast durchweg positive Rückmeldungen erhalten. Bei zwei Dritteln der Umfrageteilnehmer handelte es sich um Ärzte, bei einem Viertel um Ärzte in Weiterbildung. Auch einige Fachkrankenpfleger und Rettungsassistenten haben den Fragebogen zurückgesandt.

\section{Durchschnittsnote 1,74}

Insgesamt wurde die Zeitschrift mit einer Durchschnittsnote von 1,74 bewertet. Ein Großteil der Teilnehmer wünscht sich die Publikation der Beiträge in deutscher Sprache. Über $80 \%$ finden die Rubrik Leitthemen sehr wichtig - dies ist für die Herausgeber und den Verlag eine schöne Bestätigung der Umstellung auf das Leitthemenkonzept. Ebenfalls als sehr wichtig erachten die Umfrageteilnehmer die Publikation von Leitlinien, auch in gekürzter oder kommentierter Fassung.

\section{(2) Das Leitthemenkonzept überzeugt die Leser}

Die vielen Themenvorschläge der Leser waren auch für die Leitthemenplanung des nächsten Jahrgangs sehr hilfreich. Im zweiten Halbjahr 2001 erwarten Sie folgende Schwerpunktthemen: Organisation und Management einer Intensivstation (ICU), Der alte Mensch in der Intensivmedizin, Bildgebung auf der ICU und Gerinnungsstörungen / Blutungen.

In - Infobox 1 finden Sie eine Vorschau auf das Jahr 2012.

Wir sind aber auch dankbar für manche kritische Anmerkung, nur so können wir die Intensivmedizin und Notfallmedizin ständig weiterentwickeln und den Bedürfnissen ihrer Leser anpassen.
Unter allen Einsendern wurden als Dankeschön 10 attraktive Preise verlost.

Der 1. Preis, „Die Intensivmedizin“von H. Buchardi et al., geht an Frau Rares aus Frechen. Über den 2. und 3. Preis, „Praxis der Intensivmedizin“ von W. Wilhelm, freuen sich Herr Watermann aus Ludwigsburg und Herr Salam aus Frankfurt.

Wir bedanken uns bei allen Leserinnen und Lesern, die an der Umfrage teilgenommen haben, und wünschen auch weiterhin eine informative Lektüre mit unserer Zeitschrift.

Ihre Redaktion Intensivmedizin und Notfallmedizin

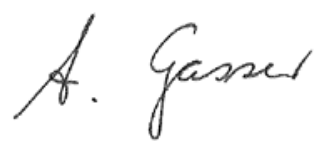

Dr. A. Gasser

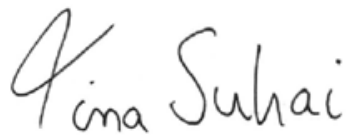

Dr. T. Suhai

\section{Infobox 1 Themenvorschau 2012}

Heft 1/2012 Für und Wider von Scores in der Intensiv- und Notfallmedizin

Heft 2/2012 Notfälle bei Schwangeren und bei der Geburtshilfe

Heft 3/2012 Chronisch-obstruktive Lungenerkrankung (COPD)

Heft 4/2012 Der Mensch im Mittelpunkt (Kongressheft)

Heft 5/2012 Rhythmusstörungen

Heft 6/2012 Endokrinologie

Heft $7 / 2012$ Beatmungsstrategien

Heft 8/2012 Airwaymanagement

(Änderungen vorbehalten) 